Graduate Thesis Report

\title{
Design, development, and evaluation of a serious video game to promote visitors' engagement in a museum exhibition context
}

\author{
Jessica Cordova-Rangel, Karina Caro
}

Published: 30 November 2021

\begin{abstract}
Museums have different challenges form a lack of funding and staff to a decrease in visitors. Due to the lack of interest from visitors, museums have created more enjoyable experiences for the public. The literature has shown that serious games are beneficial to visitors, as they can both encompasses entertainment and learning. On the other hand, this technology is mainly designed without the opportunity to allow for constant changes, resulting in a short life span. In this research, we propose the design and development of a serious video game for Caracol Museo de Ciencias, inspired by escape room game mechanics, which aims to promote visitors engagement and to provide them with a different game experience every time they visit the museum, through the continuous updating of the game by museum staff with the help of a web authoring tool.
\end{abstract}

\section{Keywords:}

Design Thinking; Museums; Engagement; Serious Games; Authoring Tool; Escape Rooms.

\section{Introduction}

Museums have shifted from places where visitors are passive participants to places where visitors engage actively in the exhibitions. The use of interactive exhibitions has become of high interest to visitors, and these types of exhibitions generally involve the use of technology [12]. A tool that the literature has proven to be successful is the utilization of serious games [2], which can be described as games that support the player to achieve specific learning goals (besides entertainment) through a joyful experience. Aside from their educational component, serious games can also contribute to increasing the engagement [17] with the elements of the museum exhibitions, and thus, improve the visitors' experience. This allows for Visitors that are highly engaged to accomplish a goal increases their likelihood of playing the game again. However,

Cordova-Rangel, Jessica., Caro, Karina.

Universidad Autónoma de Baja California (UABC)

Ensenada, Mexico

jessica.cordova.rangel@uabc.edu.mx, karina.caro@uabc.edu.mx the visitors' engagement in museums can become a challenge, as museums generally lack funding that does not allow them to update the exhibitions' content and regularly provide different experiences. Such is the case of Caracol Museo de Ciencias ${ }^{1}$, located in northwest Mexico. However, the museum is willing to incorporate new technologies as it is an interactive science-oriented museum. Therefore, the motivation of this research is the design and development of a serious game to promote visitors' engagement at a museum exhibition and the creation of a tool for museum staff for the purposes of updating the content available in the activities in the serious game.

\section{Background and Related Work}

According to the International Council of Museums (ICOM), a museum is an institution which "exhibits the tangible and intangible heritage of humanity and its environment, for education, study and enjoyment" [11]. In this section, the term "engagement" is described, and we elaborate on how it fits in the context of this research. Also, we share some examples that have been reported in the literature regarding interactive technology and games in the museum context.

\subsection{Engagement}

In the literature, there is no consensus in the definition of engagement in a museum context. Some of the most common elements related to engagement are the exploration [19] and time spent in the museum exhibition as it is considered that "the more time a participant spends doing something, the greater their level of engagement in the task" [18]. A definition of engagement for this project is based on the APE project where they propose the concept of Active Prolonged Engagement [9], understanding it as the participation of visitors with the museum elements and collaboration with other visitors.

\subsection{Technology and Games}

Different types of technologies have been developed and implemented for museums; some have been through the user's own devices, so it does not represent an additional investment for the museum. Some examples of these are presented in Luna et al. (2020), where $95.5 \%$ of the apps researched for the Mexican museum market were informative apps, while only $13.3 \%$ had to do with games in an app format [16].

${ }^{1}$ https://sic.cultura.gob.mx/ficha.php?table=museo\&table id=620 
According to [6], the benefits of using gaming elements in a museum can increase visitor interest. A serious game is a type of game that, although it considers entertainment, has a different goal, for example, an educational or health objective [22]. In this sense, a serious game employed in a museum context is the Puzzle and Mystery types [5]. In these games, the player has to find the solution to puzzles according to the clues provided and the information within the museum exhibition. Examples of projects involving these games are the Scavenger Hunts game [13], an interactive treasure hunt where a group of 11 participants aged 9 and 10 years old played the role of being detectives. The results showed that participants actively searched for the answer rather than guess. Some difficulties that arose in the project were related to technical issues and the disadvantage of depending on the availability of devices in the museum. The other example is The Quest [3] for a temporary installation, inspired by the escape room game mechanics where visitors solve riddles and once, they solve the challenges, they must submit their answer in a shared game terminal. Some results showed that visitors spent more time in that exhibition compared to the others. Nevertheless, in the initial iteration, it was hard for visitors to understand the game. However, neither of those examples provide the opportunity for the museum's staff to update the content of the video game.

As it can be seen, some efforts have been made to foster visitors' engagement to the museums, but there are still opportunities for these types of efforts to be sustainable and scalable through time and user-friendly to museums' staff to enable updates

\section{Research Objective}

The main goal of this research is to design, develop and evaluate a serious video game to promote visitors' engagement at the museum. The specific objectives are presented next.

- Identify visitors' profiles and design features that must have a serious video game for the Caracol museum.

- Identify the design characteristics that the serious video game should have to make interactive challenges reusable.

- Design the interactive challenges of the serious video game according to the profiles of attendees at the Caracol museum.

- Develop the interactive challenges of the serious video game and the web authoring tool for the Caracol museum.

- Evaluate the relationship between visitors' engagement and the user experience of the serious video game in the Caracol museum.

\section{Methods}

We are following the Design Thinking methodology [21], which is a user-centered design approach that allows iteration and contributes to "resolve complex problems" [7] by understanding the needs of users [1] and developing "fittable solutions" [14]. Although we did not find in the literature projects for museums that employed the Design Thinking methodology, we opted for this methodology due to its several advantages and the proposed potential solution that can emerge from applying this methodology.
Design Thinking consists of five phases: (1) Empathize, (2) Define, (3) Ideate, (4) Prototype, and (5) Test. Next, we describe what we did in each phase

Empathize: In this stage, two semi-structured interviews with members of the Caracol museum, documentation analysis, an online questionnaire for visitors, and observation of visitors during a visit to the exhibition halls, were employed to acquire deep knowledge about the museum visitors' profiles and the Caracol museum's context.

Define: In this stage, the information and data collected from the previous phase are analyzed through qualitative techniques, including open coding and axial coding [4] for the interviews. The questionnaires were analyzed using descriptive statistics and qualitative techniques for some open-ended questions. In addition, the persona's method [10], for understanding users' needs, behaviors and so on, was also used to create four fictional characters to represent different user types that might use the game $^{2}$.

Ideate: The goal of this phase is to generate some possible ideas for the serious game using the results of the Define Phase. In this phase, a two-hour-long co-design session was conducted with five staff members of the Caracol museum using brainstorming technique and Crazy-8's method [8], a fast-sketching activity that invites participants to design eight different screens of the game in under 8 minutes, a minute per screen.

Prototype: In this phase, the proposals of the co-designing session of the game are considered to formulate a proposal and convert it into a low-fidelity prototype using a prototyping tool, like Figma, to evolve it into a high-fidelity prototype eventually.

Test: This phase will be continuously iterated with the previous phase. The prototype of the game and the authoring will be evaluated by members of the museum staff and potential visitors in validation sessions to measure the perceived usefulness, perceived use, and usability through the Technology Acceptance Model (TAM) [20] and the System Usability Scale (SUS) [15] questionnaires. Once the high-fidelity prototype is completed, the game will be tested with the museum's visitors and evaluated with surveys about users' experience and engagement.

\section{Current Results}

In this section, we describe the design considerations that emerged from the Define phase, the design proposals resulting from the Ideate phase, and the low-fidelity prototype from the Prototype phase.

\subsection{Design Considerations}

Based on the data analysis from interviews and the questionnaire, the following design considerations aroused to be considered in the serious game:

- It must provide entertainment; however, the education component should be the most relevant.

- It should be designed to be used for a short time so the interaction with the mobile devices would not distract visitors from the essential elements of the exhibition, as it should be played in situ (in the museum).

- Some games according to the interests of potential visitors are: find the differences, puzzles, treasure hunt, memory game, and trivia.

\footnotetext{
${ }^{2}$ Examples of Personas.
} 
- The design of the interactive challenges should be of low maintenance; therefore, there is a need for having mini games that allow for the development of reusable templates.

\subsection{Design Proposals}

From the co-design session, two design proposals emerged: Underwater Adventure (Figure 1- a) and The Migration Journey (Figure 1-b).

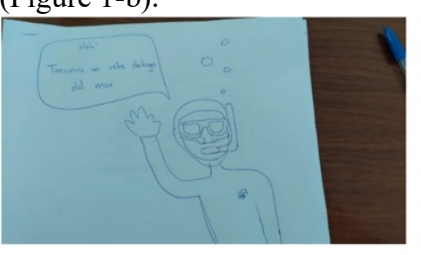

a. Main Character from Underwater Adventure

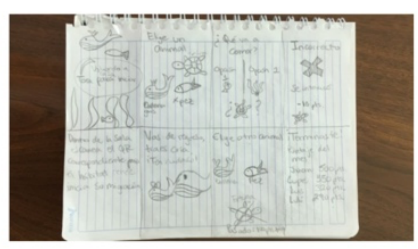

b. Levels from the Migration Journey
Figure 1. Examples of the brainstorming and crazy 8's methods used during the co-design session.

Some relevant characteristics of these proposals includes:

- A main character, a diver, who guides the player through the storyline.

- $\quad$ Encouraging participation from the youth by providing an individual leaderboard and a group leaderboard by schools in the area.

- Different levels related to the topics of the Sea Hall.

\subsection{The Aventura Marina Game}

Aventura Marina game (Figure 2 - a) is a serious game for mobile devices for supporting visitors' engagement in the Caracol museum. The game's storyline consists of participating in an adventure to unlock a treasure chest (Figure $1-\mathrm{d}$ ), which is done with the help of the story's main character (Figure 2 - c), a scuba diver that players can select as having the profession of a scientist or an environmental activist (Figure 2 - b). The challenges the player has to encounter are related to the exhibition's topics: oceanography, Marine flora and fauna, and the relation between the human being and the sea; thus, the game has to be played by visitors who are physically in the place.

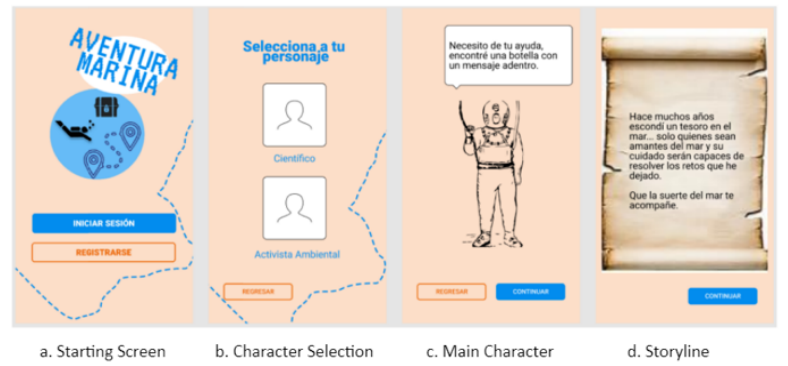

Figure 2. Screens from the prototype of Aventura Marina.

The game mechanics of Aventura Marina is that players should solve five short, interactive challenges that are based on the escape room mechanics. The challenges include puzzles, trivia, memory games, fill in the blanks, among others. Next, we present an example of one of the challenges.

All the challenges start with a situation (Figure 3 - a), then a solution (Figure $3-b$ ), feedback for the player is given (Figure 3 c), and finally, it all comes to a reward for that challenge (Figure 3 - d). Once all the challenges are completed, players must unlock the treasure chest by entering a six-digit password (one of these digits is provided by the tour guide as means to only allow for the game to be played within the museum). The game congrats the players for their participation and players receive a collectable badge.

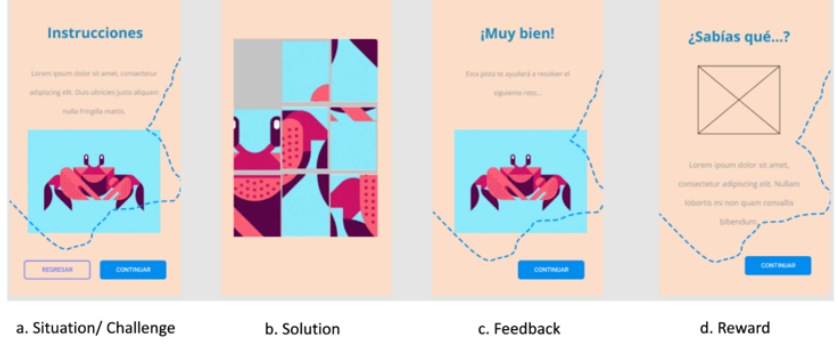

Figure 3. Parts of a mini game in Aventura Marina.

The game dynamics of Aventura Marina is that players earn stars if they solve the puzzles, but they do not lose stars if they make a mistake. This is a way to avoid players' frustration. The stars are used to know the player's position and the overall position according to which school they belong to on the leaderboard. In addition to the stars, they also receive badges related to the theme of the Sea Hall after finishing the five challenges and opening the treasure chest.

\subsection{Validation session}

A two-and-a-half-hour-long validation session for the low-fidelity prototype of Aventura Marina was put up for discussion and to receive feedback from six members of the Caracol museum staff. The results of this validation session are still undergoing analysis and will be considered to iterate another version of Aventura Marina

\section{Potential Evaluation Methods}

The design proposal of Aventura Marina is a means to foster engagement with the public that visits the museum because the content of the video game can be updated by the museum's staff through the web authoring tool, and with that, in any new visit, players will have the chance to experience different content in the video game that will motivate them to solve the challenges and ultimately, increase their interest in the exhibition.

In the literature, some of the aspects represented in the evaluation of engagement are related to the time spent in the museum exhibition, the exploration of the area, and discussions around the exhibition. However, in the context of the Caracol museum, it is not possible to consider the length of time spent in an exhibit because the current COVID-19 guidelines limit the length of time visitors can spend in the museum. In the meantime, we will start to develop the interactive challenges and the web authoring tool. Once deployed, there will be an evaluation of the game with the museum's visitors to measure the usability of the game and the relation between visitor engagement and the experience of using a serious video game in the Caracol museum as well as an evaluation with the museum's staff regarding the usability of the web authoring tool.

\section{Required feedback}

In the context of COVID-19, I would be interested in analyzing alternatives and receiving suggestions for the serious video game's evaluation stage and guidelines in methods to develop a userfriendly authoring tool.

\section{References}

[1] Ahmad A Naufal and Amalia Suzianti. 2019. Design thinking approach for product innovation design of 
educational toys. In Proceedings of the 2019 5th

International Conference on E-business and Mobile Commerce. 69-74.

[2] Anderson, E. F., McLoughlin, L., Liarokapis, F., Peters, C., Petridis, P., \& De Freitas, S. (2010). Developing serious games for cultural heritage: a state-of-the-art review. Virtual reality, 14(4), 255-275.

[3] Back, J., Back, S., Bexell, E., Stanisic, S., \& Rosqvist, D. (2019, October). The quest: An escape room inspired interactive museum exhibition. In Ext. Abstracts of CHIPLAY 2019 (pp. 81-86).

[4] Corbin, J. M., \& Strauss, A. (1990). Grounded theory research: Procedures, canons, and evaluative criteria. Qualitative sociology, 13(1), 3-21.

[5] Din, H. W. H. (2006). Play to learn: exploring online educational games in museums. In ACM SIGGRAPH 2006 Educators program (pp. 13-es).

[6] Doran, K., Boyce, A., Hicks, A., Payton, J., \& Barnes, T. (2012, June). Creation of a game-based digital layer for increased museum engagement among digital natives. In GAS 2012 (pp. 31-34). IEEE.

[7] Eunice Sari and Adi Tedjasaputra. 2018. Design Thinking 101: A Strategy for Intelligent System Innovation. In Proceedings of the 4th International Conference on HumanComputer Interaction and User Experience in Indonesia, CHIuXiD'18. 122-125.

[8] Gkatzidou, V., Giacomin, J., \& Skrypchuk, L. (2021). Automotive Human Centred Design Methods. De Gruyter.

[9] Horn, M., Atrash Leong, Z., Block, F., Diamond, J., Evans, E. M., Phillips, B., \& Shen, C. (2012, May). Of BATs and APEs: an interactive tabletop game for natural history museums. In Proc. SIGCHI (pp. 2059-2068).

[10] Interaction Design Foundation. 2021. What are Personas? https://www.interaction-design.org/literature/topics/personas

[11] International Council of Museums. 2007. Museum Definition. https://bit.ly/3lokoeY

[12] Kuflik, T., Stock, O., Zancanaro, M., Gorfinkel, A., Jbara, S., Kats, S., ... \& Kashtan, N. (2011). A visitor's guide in an active museum: Presentations, communications, and reflection. JOCCH, 3(3), 1-25.

[13] Kwak, S. Y. (2004). Designing a handheld interactive scavenger hunt game to enhance museum experience. Michigan State University.
[14] Lauriane Pereira, Rafael Parizi, Matheus Prestes, Sabrina Marczak, and Tayana Conte. 2021. Towards an understanding of benefits and challenges in the use of design thinking in requirements engineering. In Proceedings of the 36th Annual ACM Symposium on Applied Computing. 1338-1345.

[15] Lewis, J. R. (2018). The system usability scale: past, present, and future.Int. J. Hum.-Comput. Interact.., 34(7), 577-590.

[16] Luna, Ú., Herrera, P. J. C., González, A. Z., \& Etxeberria, A. I. (2020). Apps, educación y patrimonio en México. Análisis de situación y estudio comparativo con el caso español. Aula Abierta, 49(1), 9-16.

[17] Nicholson, S. (2015). Peeking behind the locked door: A survey of escape room facilities.

[18] Nelson, B. C., Bowman, C. D., Bowman, J. D., Cortés, L. E. P., Adkins, A., Escalante, E., ... \& Su, M. (2020). Ask Dr. Discovery: The impact of a casual mobile game on visitor engagement with science museum content. Educational Technology Research and Development, 68(1), 345-362.

[19] Rowe, J. P., Lobene, E. V., Mott, B. W., \& Lester, J. C. (2017). Play in the museum: Design and development of a game-based learning exhibit for informal science education. IJGCMS, 9(3), 96-113.

[20] Silva, P. (2015). Davis' technology acceptance model (TAM)(1989). Information seeking behavior and technology adoption: Theories and trends, 205-219.

[21] Tim Brown et al. 2008. Design thinking. Harvard business review 86, 6 (2008), 84.

[22] Vocaturo, E., Zumpano, E., Caroprese, L., Pagliuso, S. M., \& Lappano, D. (2019, January). Educational Games for Cultural Heritage. In VIPERC@ IRCDL (pp. 95-106).

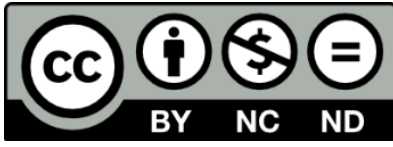

(C) 2021 by the authors. This work is licensed under the Creative Commons AttributionNonCommercial-NoDerivatives 4.0 International License. To view a copy of this license, visit http://creativecommons.org/licenses/by-nc-nd/4.0/ or send a letter to Creative Commons, PO Box 1866, Mountain View, CA 94042, USA. 